Supporting information

\title{
Polymeric Nanostructure Compiled with Multifunctional Components to Exert Tumor- targeted Delivery of Anti-angiogenic Gene for Tumor Growth Suppression
}

Qixian Chen, ${ }^{a, b, \dagger, *}$ Ruogu Qi ${ }^{c, \dagger}$ Xiyi Chen, ${ }^{d}$ Xi Yang, ${ }^{e}$ Xing Huang, ${ }^{f}$ Haihua Xiao, ${ }^{c}$ Xinhuan Wang, Wenfei Dong, ${ }^{a *}$

${ }^{a}$ CAS Key Laboratory of Bio-Medical Diagnostics, Suzhou Institute of Biomedical Engineering, Suzhou 215163, China, ${ }^{b}$ Deparment of Chemistry, Massachusetts Institute of Technology Cambridge, MA 02139, USA, 'State Key Laboratory of Polymer Physics and Chemistry Changchun Institute of Applied Chemistry, Chinese Academy of Sciences, Changchun 130022, China, ${ }^{\mathrm{d}}$ School of Public Health, Dalian Medical University, No. 9 West Section Lvshun South

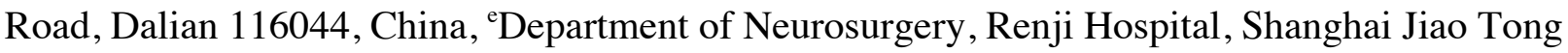
University School of Medicine, Shanghai 200127, China, ${ }^{\mathrm{f}}$ Department of Urology, Zhongnan Hospital, Wuhan University, Wuhan 430071 China

\section{Corresponding Author}

*Dr. Qixian Chen. Tel: +1-6175017710. Email: qixian@mit.edu.

*Dr. Wenfei Dong. Tel: +86-512-69588307. Email: weifeidong@126.com. 


\section{S1: Synthetic scheme of PEG-PLys}

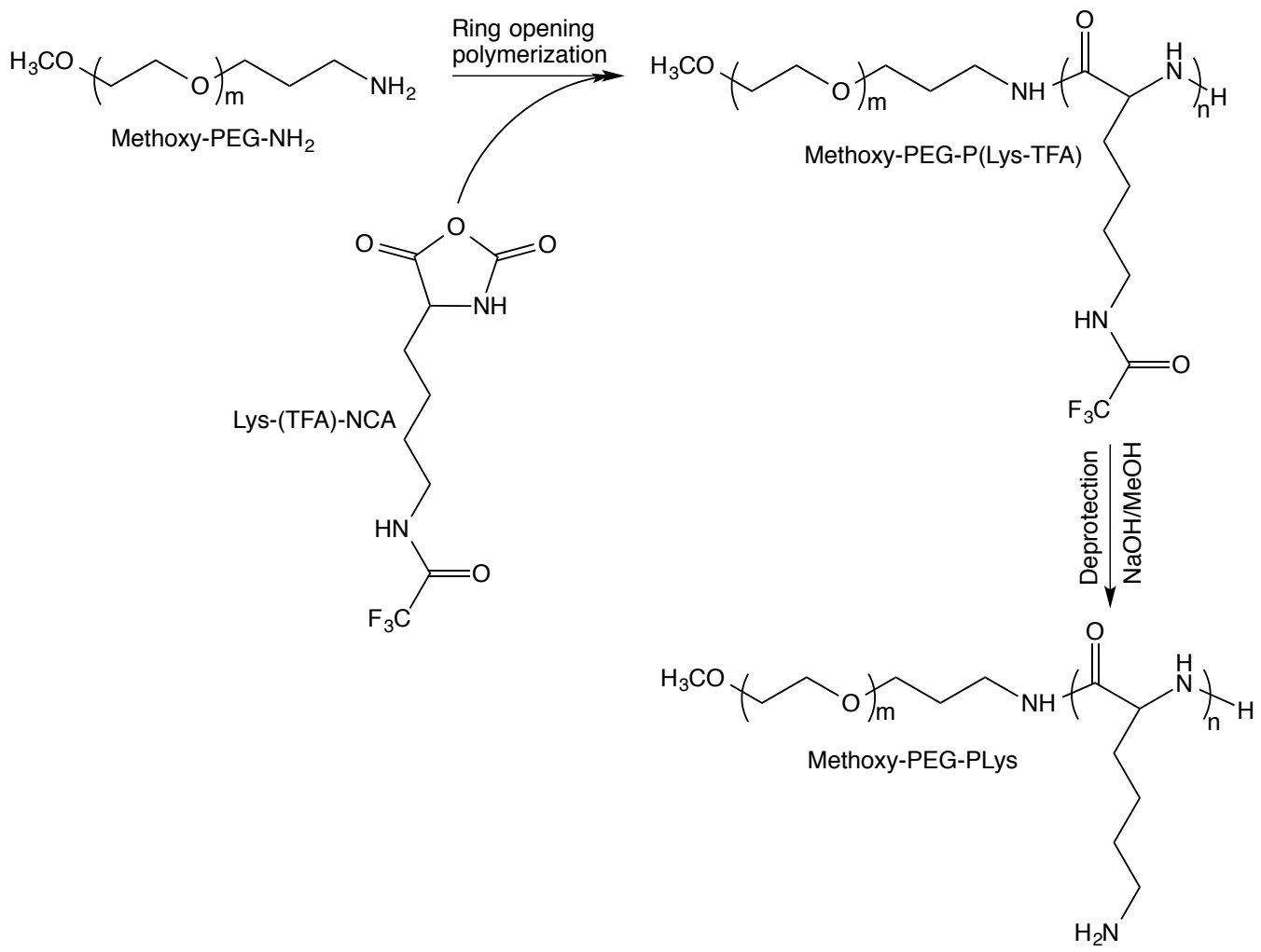

Scheme S1 Synthetic scheme to prepare block copolymer PEG-PLys by ring opening polymerization. 


\section{S2: Synthetic scheme of cRGD-PEG-PLys(SH)}

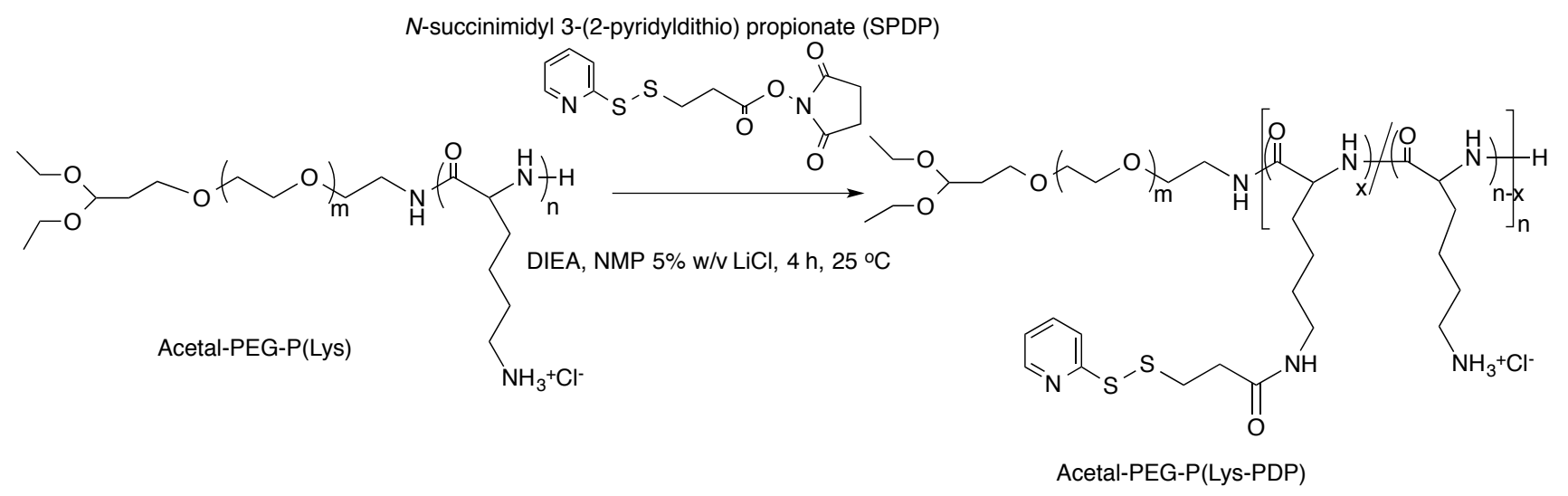

\footnotetext{
$10 \mathrm{mM}$ DTT/10 mM HEPES ( $\mathrm{pH} 7.4), 6 \mathrm{~h}, 25^{\circ} \mathrm{C}$

Dialysis $0.01 \mathrm{~N} \mathrm{HCl}$, pH 2.0
}

$10 \mathrm{mM}$ DTT/10 mM HEPES (pH 7.), $30 \mathrm{~min}, 25^{\circ} \mathrm{C}$
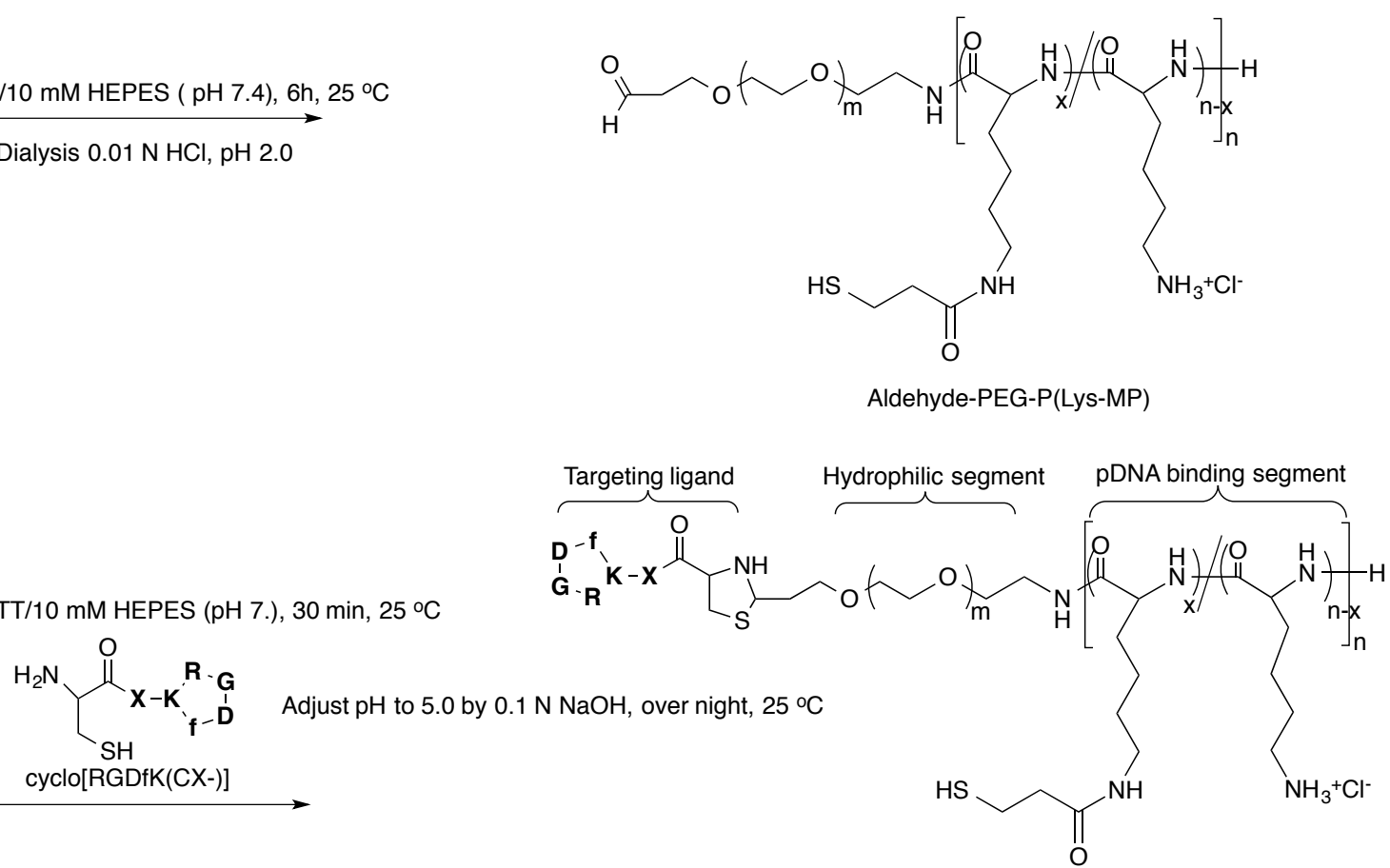

Scheme S2 Synthetic scheme to prepare block copolymer cRGD-PEG-PLys(SH). 
S3: Synthetic scheme of PNIPAM-PLys(SH)

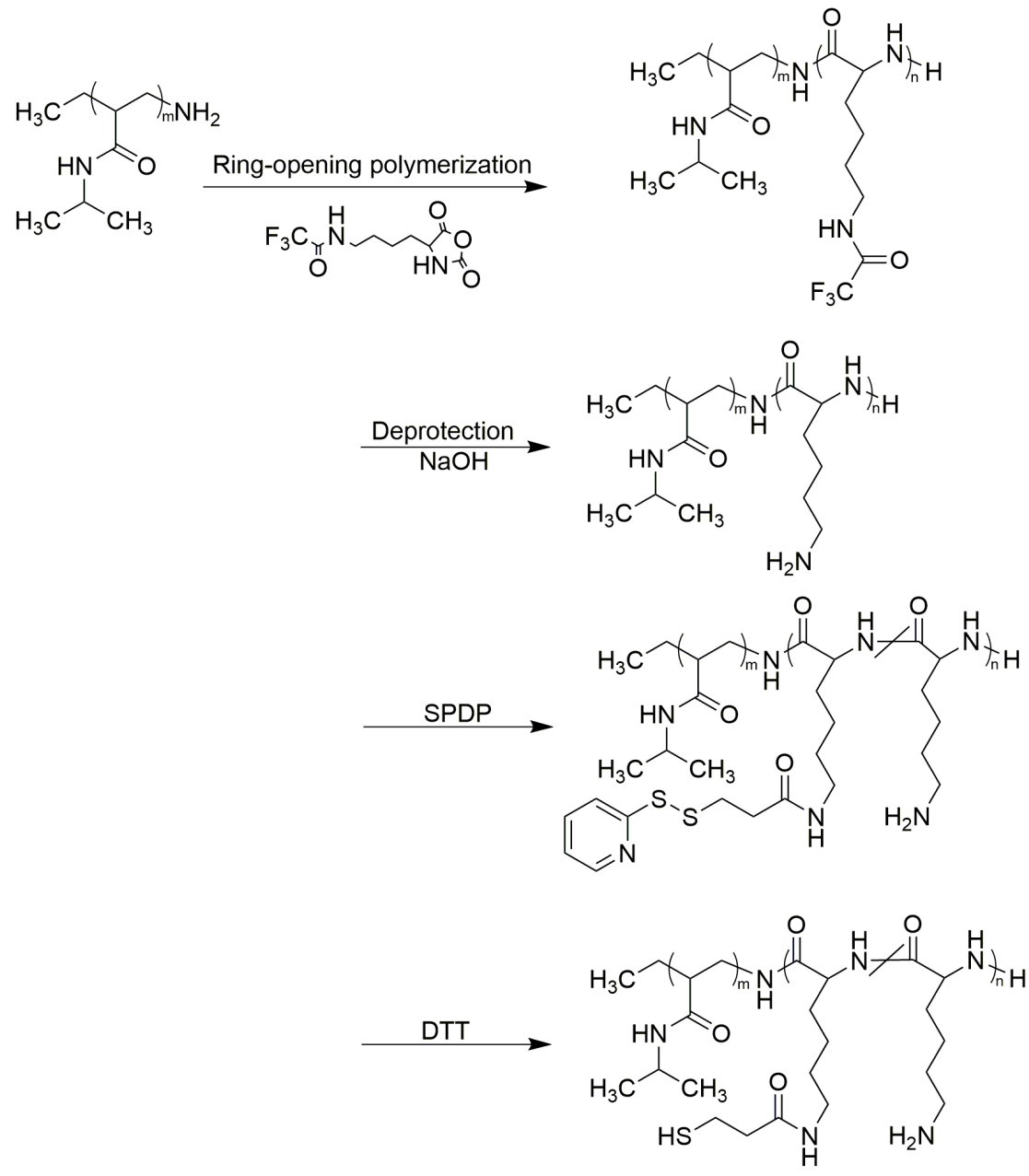

Scheme S3 Synthetic scheme to prepare block copolymer PNIPAM-PLys(SH). 
S4: ${ }^{1} \mathrm{H}-\mathrm{NMR}$ spectra

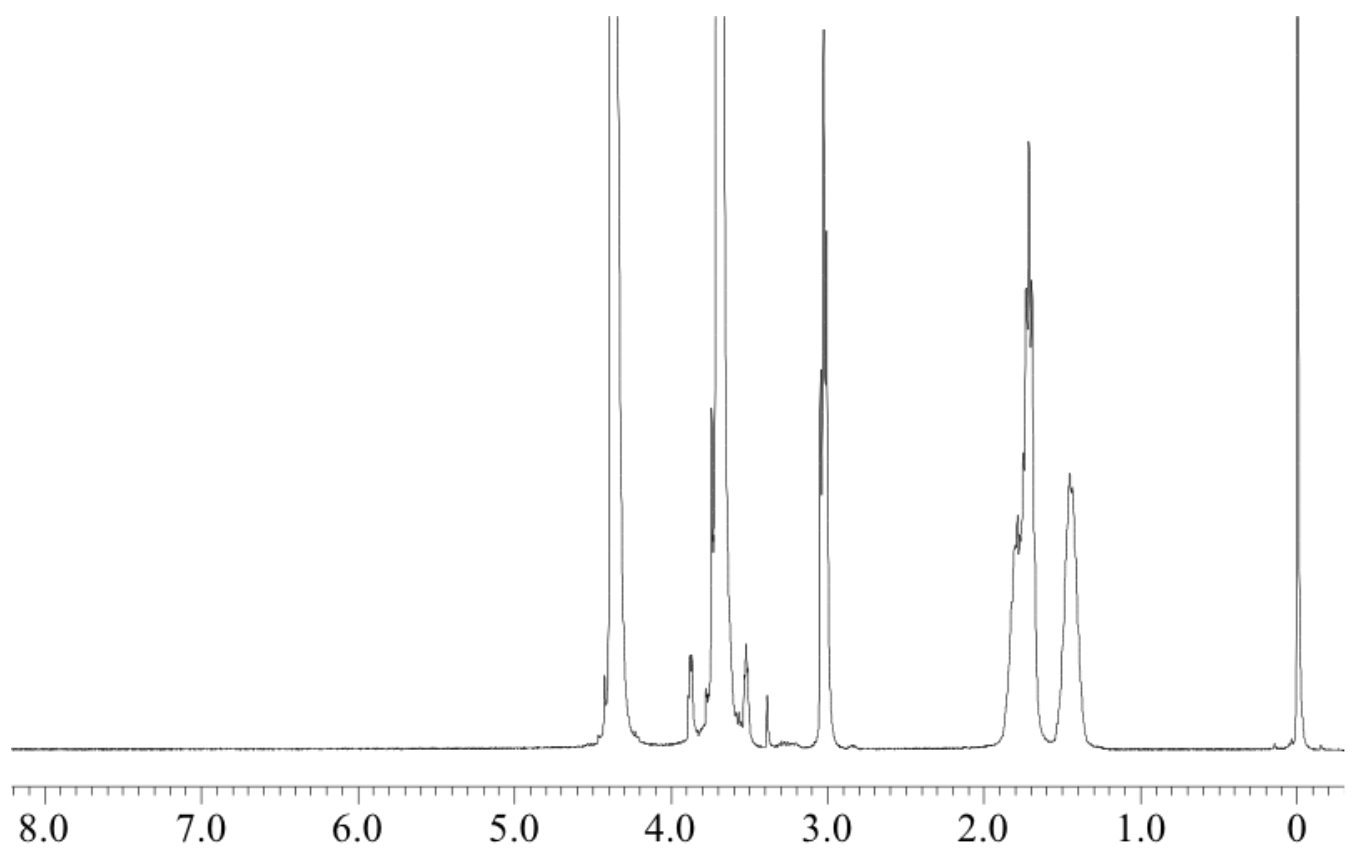

Figure $\mathrm{S1}{ }^{1} \mathrm{H}$-NMR spectra of PEG-PLys in $\mathrm{D}_{2} \mathrm{O}$ at $80^{\circ} \mathrm{C}$.

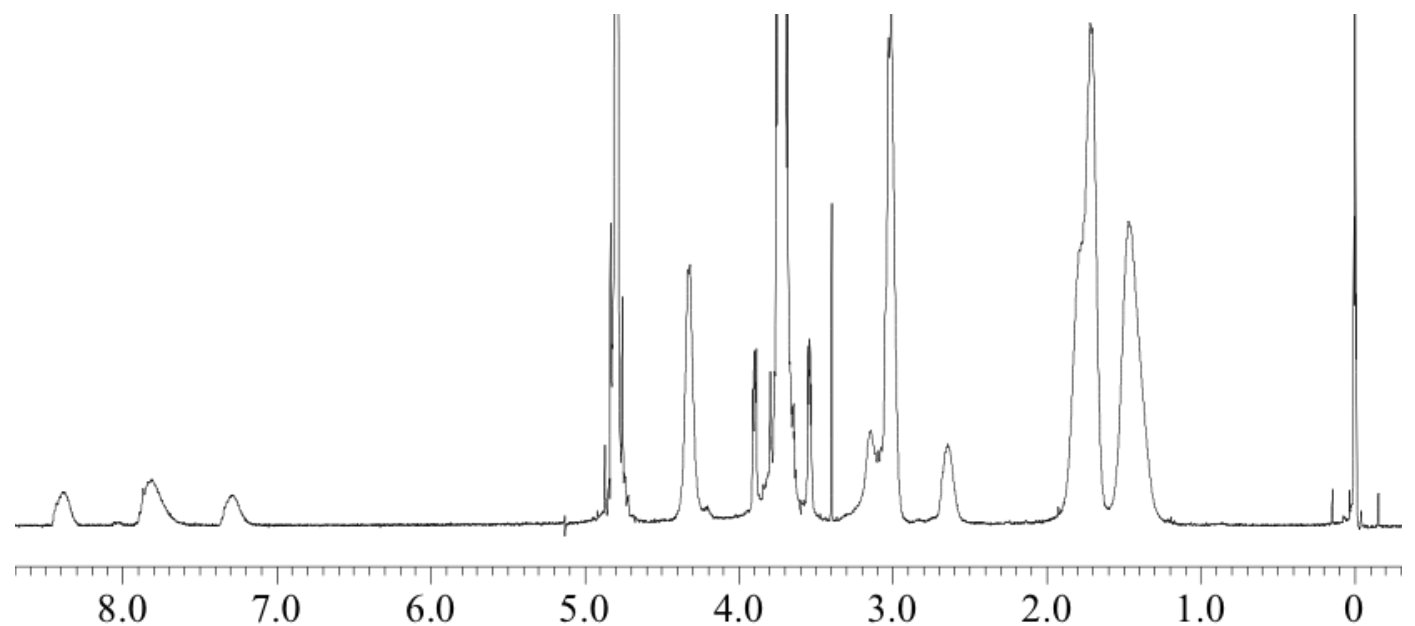

Figure S2 ${ }^{1} \mathrm{H}-\mathrm{NMR}$ spectra of PEG-PLys(PDP) in $\mathrm{D}_{2} \mathrm{O}$ at $80{ }^{\circ} \mathrm{C}$. 


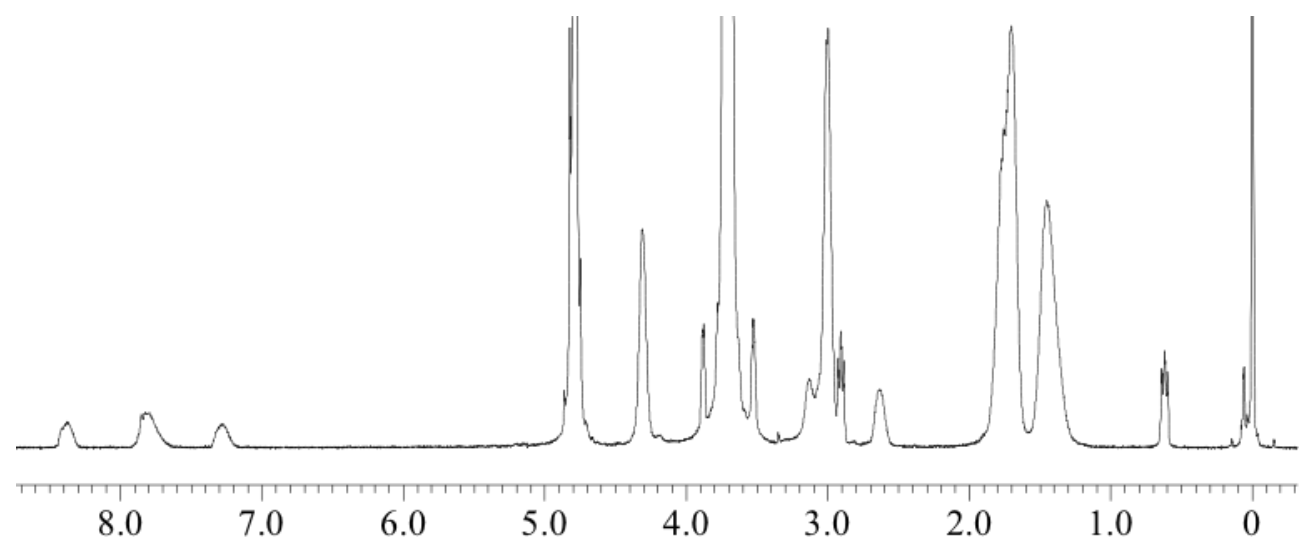

Figure S3 ${ }^{1} \mathrm{H}-\mathrm{NMR}$ spectra of acetal PEG-PLys(PDP) in $\mathrm{D}_{2} \mathrm{O}$ at $80{ }^{\circ} \mathrm{C}$.

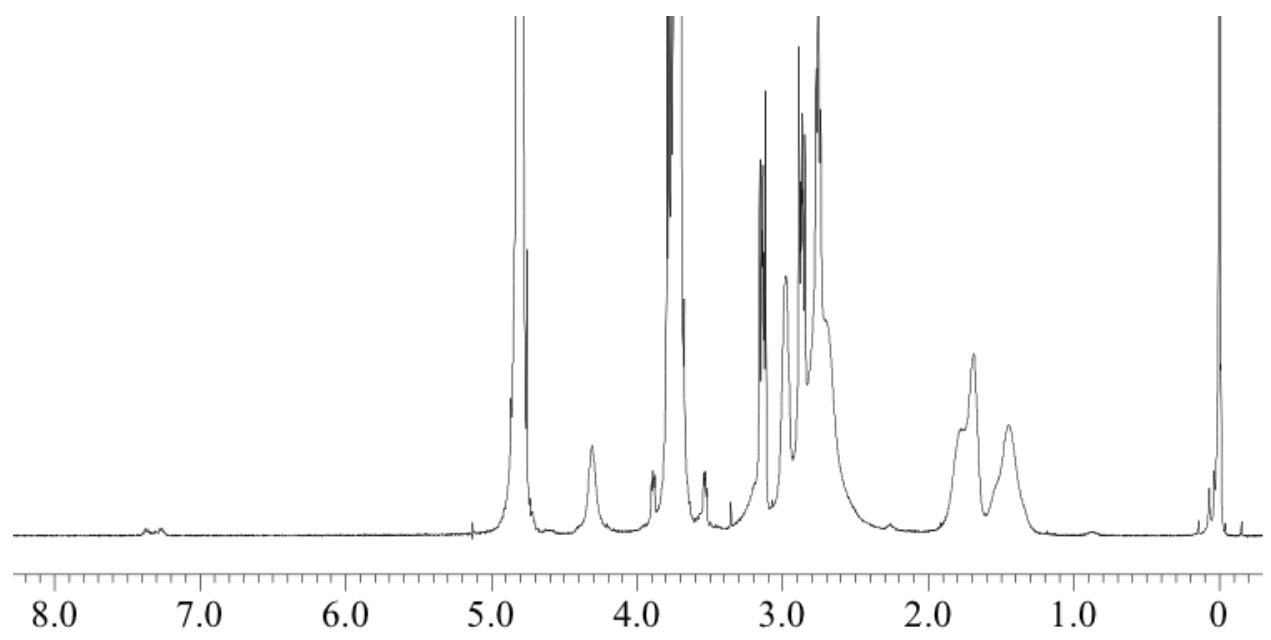

Figure $\mathbf{S 4}{ }^{1} \mathrm{H}-\mathrm{NMR}$ spectra of cRGD-PEG-PLys(SH) in $\mathrm{D}_{2} \mathrm{O}$ at $80{ }^{\circ} \mathrm{C}$.

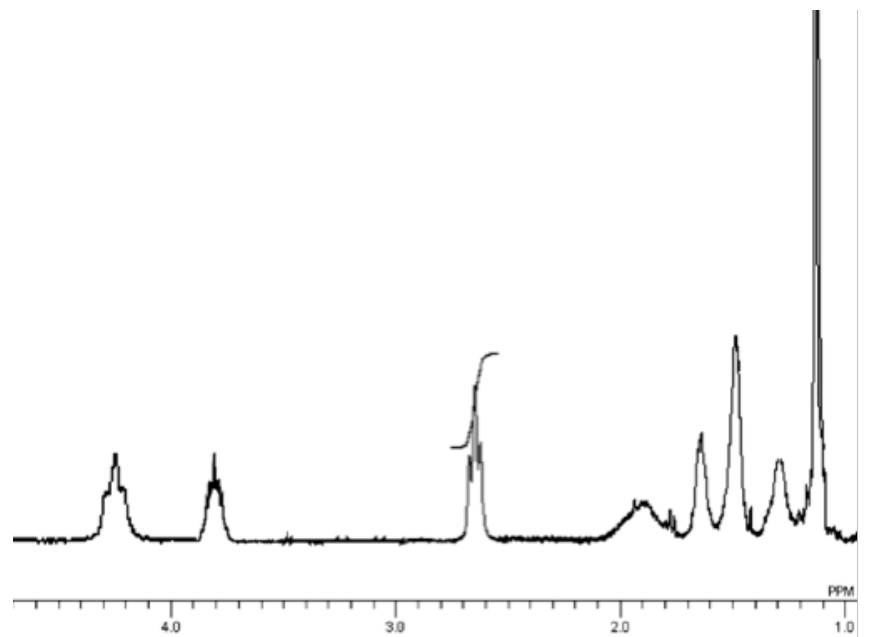

Figure S5 ${ }^{1} \mathrm{H}-\mathrm{NMR}$ spectra of PNIPAM-PLys $(\mathrm{SH})$ in $\mathrm{D}_{2} \mathrm{O}$ at $20{ }^{\circ} \mathrm{C}$. 
S5: Gel permeation chromatography (GPC)

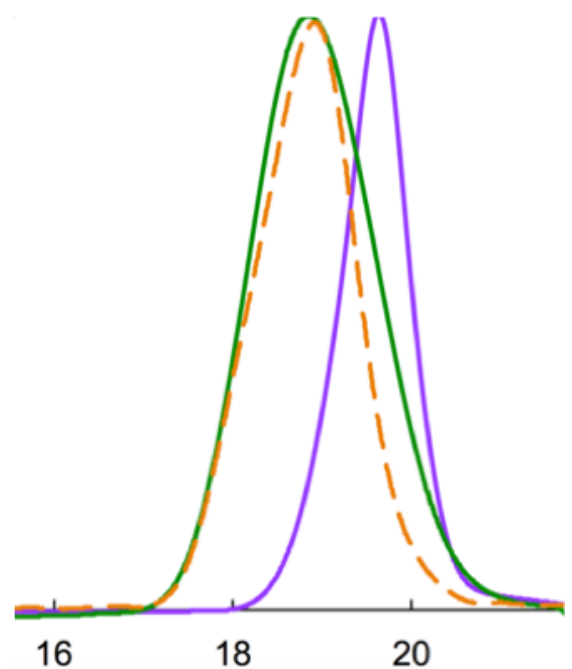

Figure S6 GPC trace of PEG-PLys (orange), cRGD-PEG-PLys(SH) (green) and PNIPAM-PLys(SH) (purple). 


\section{S6: EtBr assay for insight into pDNA release}

The relative dissociation of diverse polyplex micelles in the presence of varying concentrations of anionic heparan sulfate, under treatment of DTT or not, was estimated using an EtBr fluorescence recovery assay. Various solutions of polyplex micelles were adjusted to have a uniform pDNA concentration of 50 $\mu \mathrm{g} / \mathrm{mL}$. Heparan sulfate and EtBr solutions were prepared to have a concentration of $8.4 \mu \mathrm{g} / \mathrm{mL}$, and 100 $\mathrm{mg} / \mathrm{mL}$ in a $10 \mathrm{mM}$ HEPES buffer (pH 7.4) as stock solutions. Then, solutions of polyplex micelles were supplemented with DTT and heparan sulfate solutions, where DTT (+) samples were adjusted to have a concentration of $10 \mathrm{mM}$, the final DNA concentration and EtBr concentration were adjusted to a 20 $\mu \mathrm{g} / \mathrm{mL}$ and $3.36 \mu \mathrm{g} / \mathrm{mL}$ with $10 \mathrm{mM}$ HEPES buffer. Following incubation under dark at $4{ }^{\circ} \mathrm{C}$ for $2 \mathrm{~h}$, the fluorescence intensity of each sample was measured at $\lambda_{\mathrm{em}}=590 \mathrm{~nm}\left(\lambda_{\mathrm{ex}}=510 \mathrm{~nm}\right)$ at $25{ }^{\circ} \mathrm{C}$ using a spectrofluorometer (FP-6500, JASCO, Tokyo, Japan). All data represent the mean of three independent measurements.

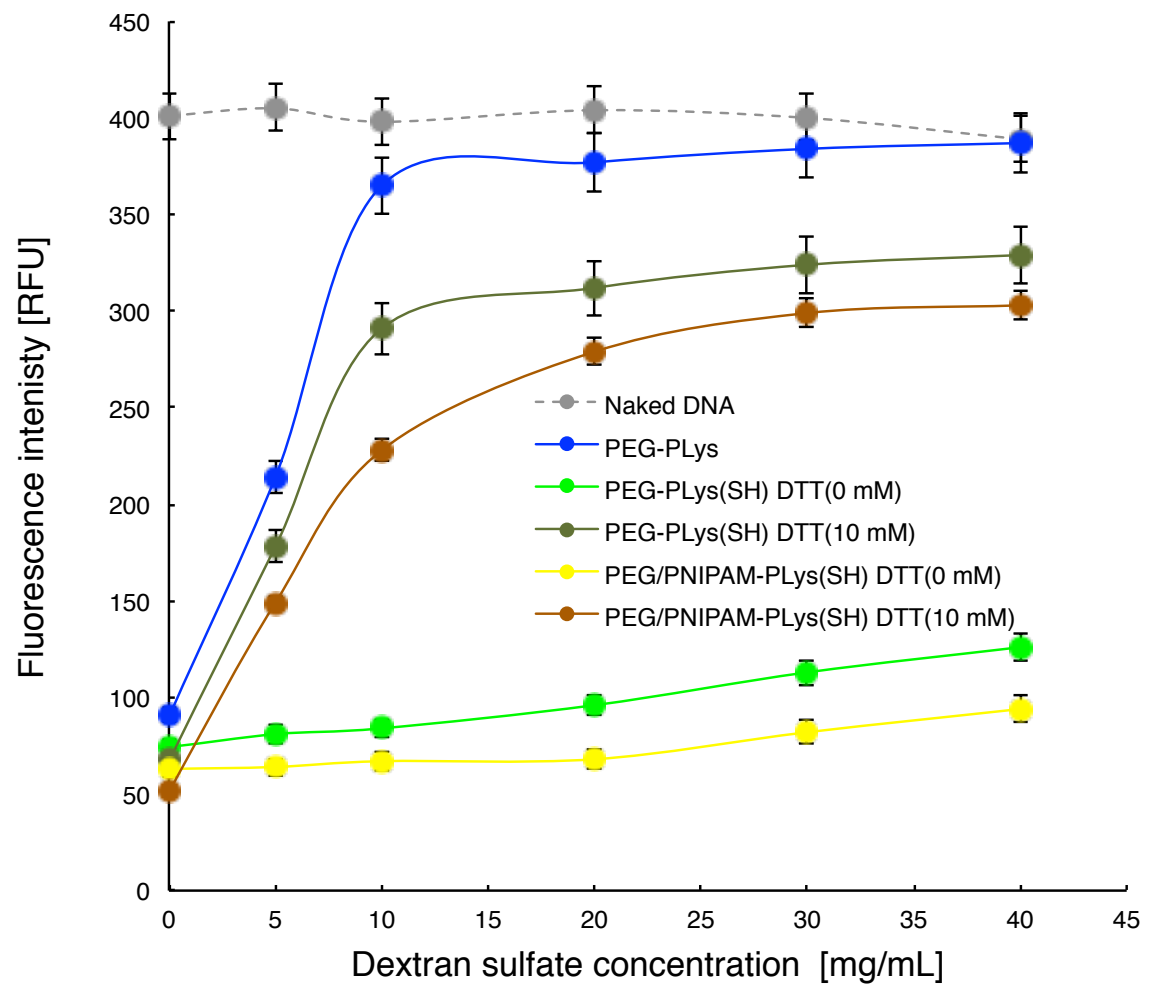


Figure S7 Insight into the facilitated DNA release from the polyplex micelles in response to the intracellular reducing milieu. The DNA releasing activity was examined by an EtBr recovery assay, where the fluorescence recovery activities of polyplex micelles in presence of EtBr were measured under treatment of DTT $(10 \mathrm{mM})$ and varying concentrations of heparan sulfate.

\section{S7: In vitro cytotoxicity}

U87 cells were plated onto 24-well culture dishes (20,000 cells/well) in $400 \mu$ DMEM containing 10\% FBS and 1\% antibiotics (penicillin and streptomycin) and incubated in a humidified atmosphere with 5\% $\mathrm{CO}_{2}$ at $37^{\circ} \mathrm{C}$. After $24 \mathrm{~h}$ of incubation, the medium was replaced with $400 \mu \mathrm{l}$ of fresh medium, followed by the addition of polyplex micelle solutions equivalent to $0.5 \mu \mathrm{g}$ of pDNA/well. After $24 \mathrm{~h}$ incubation, the medium was replaced with fresh medium, followed by another $24 \mathrm{~h}$ of incubation. The cells were washed three times with ice-cold PBS, followed by the addition of $200 \mu \mathrm{l}$ of fresh medium. Cell viability was assessed on the basis of 2-(2-methoxy-4-nitrophenyl)-3-(4-nitrophenyl)-5-(2,4-disulfophenyl)-2Htetrazolium (WST-8) reduction to WST-8 formazan by the dehydrogenase activity of viable cells using the Cell Counting Kit-8 (CCK-8) (Dojindo, Kumamoto, Japan) according to manufacturer's instructions. In brief, $20 \mu \mathrm{l}$ of the CCK-8 reagent was added to each well and allowed to develop orange-colored WST8 formazan for $2 \mathrm{~h}$. The UV absorbance of WST-8 formazan in each well was quantified at $450 \mathrm{~nm}$ using a microplate reader (Model 680, Bio-Rad, UK). The cell toxicity was expressed as the percentage of cell viability normalized against control cells treated with $10 \mathrm{mM}$ HEPES $(\mathrm{pH} 7.4)(n=4)$.

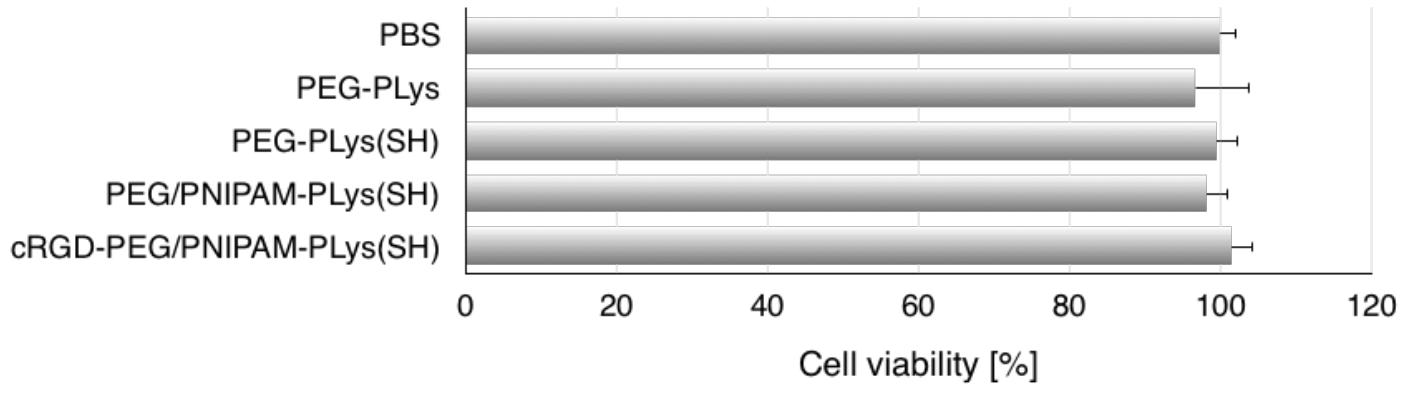

Figure S8 Cell viability of U87 cells in presence of diverse polyplex micelles. 


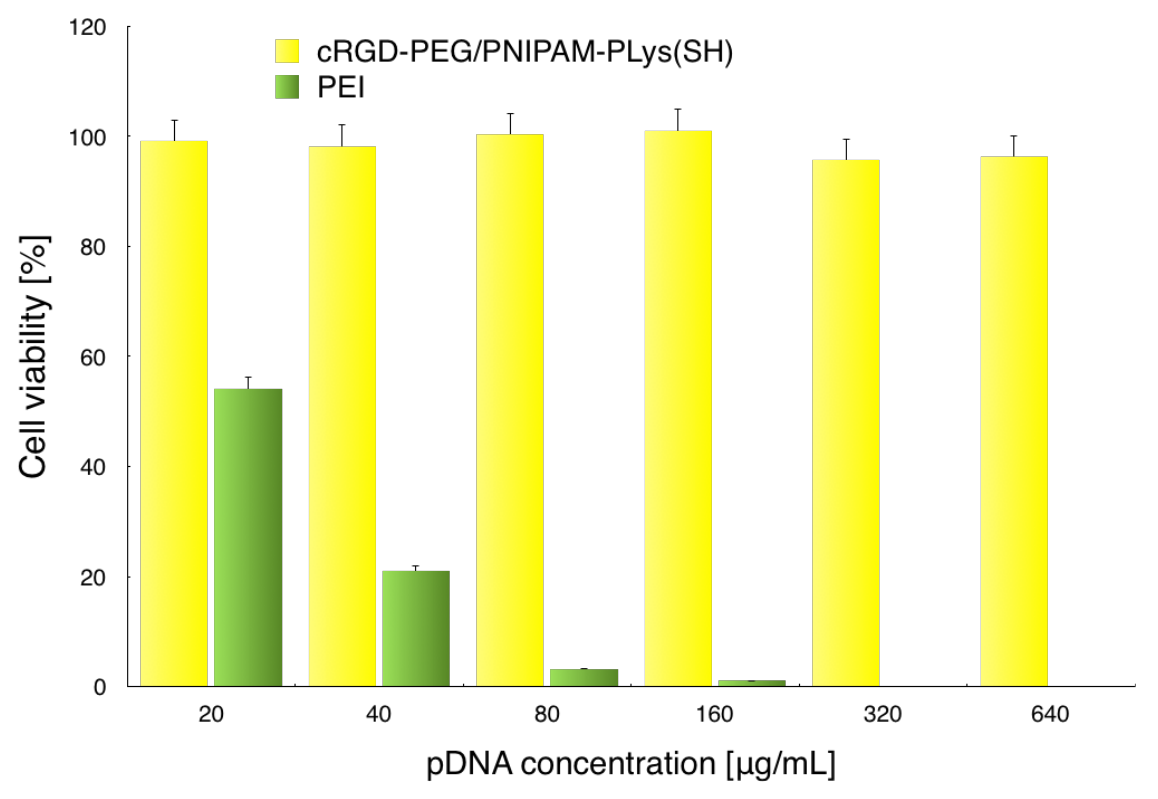

Figure S9 Cell viability of U87 cells in presence of varying concentration of cRGD-PEG/PNIAMPPLys(SH) polyplex micelle, where PEI was used as a control.

S8: Comparison of the proposed system with commercial transfection agents
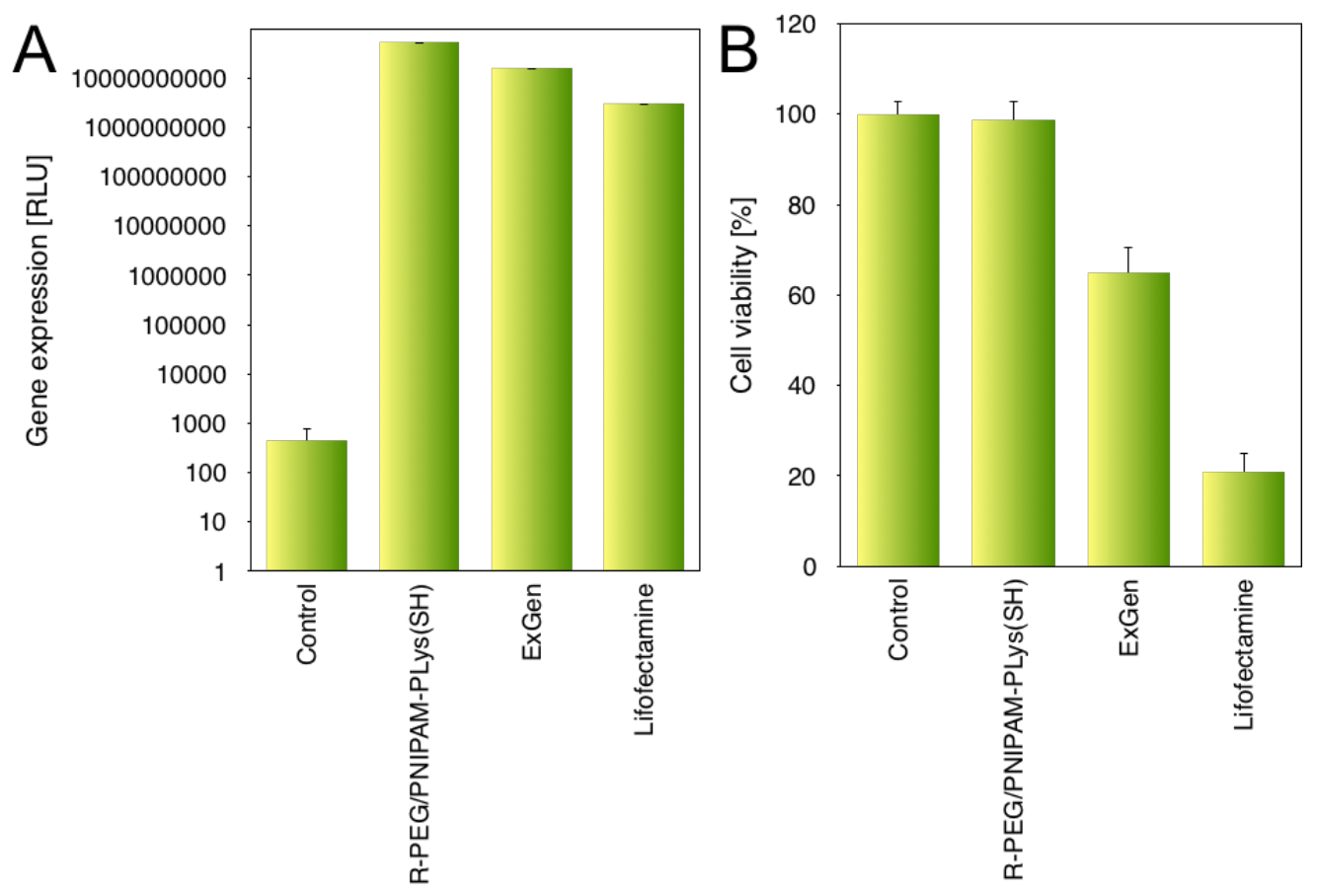
Figure S10 Cell transfection activity and cell viability of U87 cells in presence of the proposed polyplex micelles and commercial nucleic acids transfection agents. A): gene expression activity of diverse formulations in U87 cells; B): Cell viability of diverse formulations in U87 cells.

\section{S9: Biodistribution}

Polyplex micelles of PEG/PNIPAM-PLys(SH) (A) or cRGD-PEG/PNIPAM-PLys(SH) loading Cy5labeled pDNA ( $20 \mu \mathrm{g}$ of pDNA) were intravenously injected into the U87-inoculated Balb/c mice via the tail vein. Mice were sacrificed at 48 hours after injection. The tumors and other major organs were excised, homogenized with cell lysis buffer, and transferred to an opaque 98 well plate for IVIS measurement. The obtained radiant efficiency was normalized against the weight of the corresponding organs.
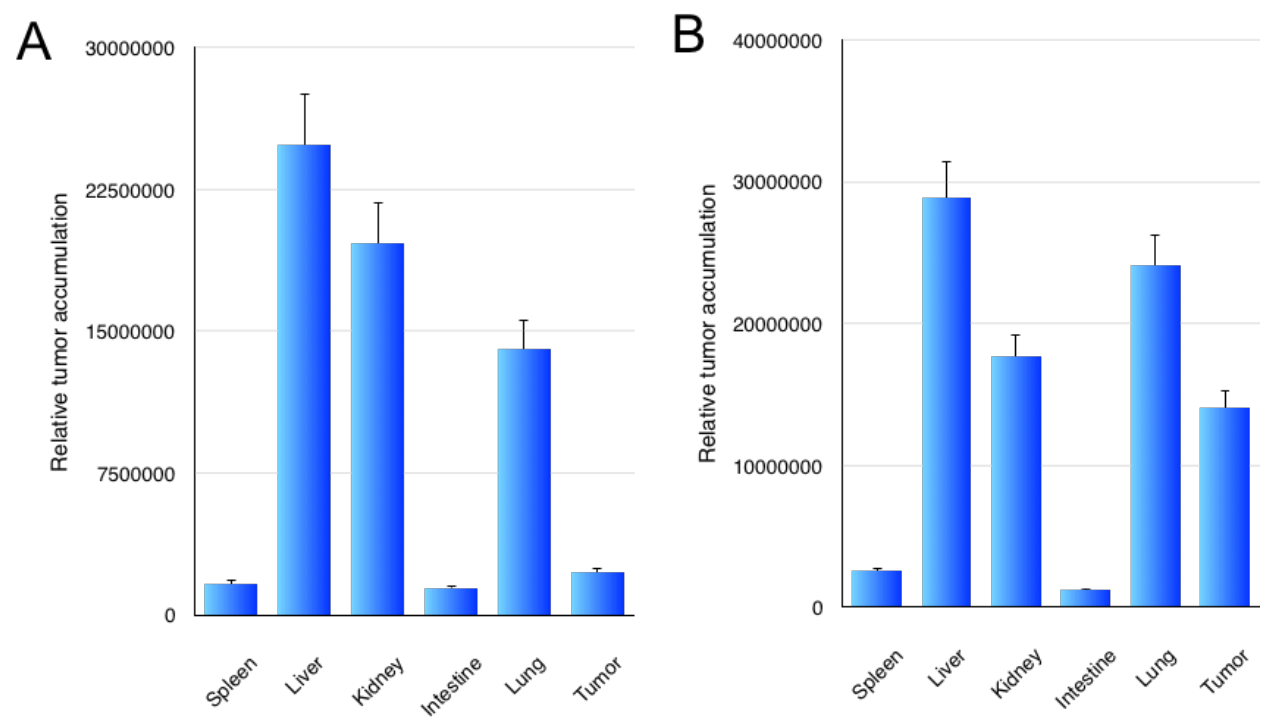

Figure S11 Biodistribution of polyplex micelle from PEG/PNIPAM-PLys(SH) (A) and cRGDPEG/PNIPAM-PLys(SH) (B) at $48 \mathrm{~h}$ post administration.

\section{S10: Body weight}

$\mathrm{Balb} / \mathrm{c}$ nude mice were inoculated subcutaneously with U87 cells $\left(10^{7}\right.$ cells in $100 \mu \mathrm{L}$ of PBS). Tumors were allowed to grow for 2 weeks till proliferative phase (the size of the tumors was approximately 75 
$\mathrm{mm}^{3}$ ). Subsequently, each sample (20 $\mu \mathrm{g}$ sFlt-1 pDNA/mouse) in $10 \mathrm{mM}$ HEPES buffer (pH 7.4) with $150 \mathrm{mM} \mathrm{NaCl}$ was intravenously injected to $\mathrm{Balb} / \mathrm{c}$ nude mice via the tail vein 3 times on days 0,3 and 6 . Body weight was recorded with a balance every five days.

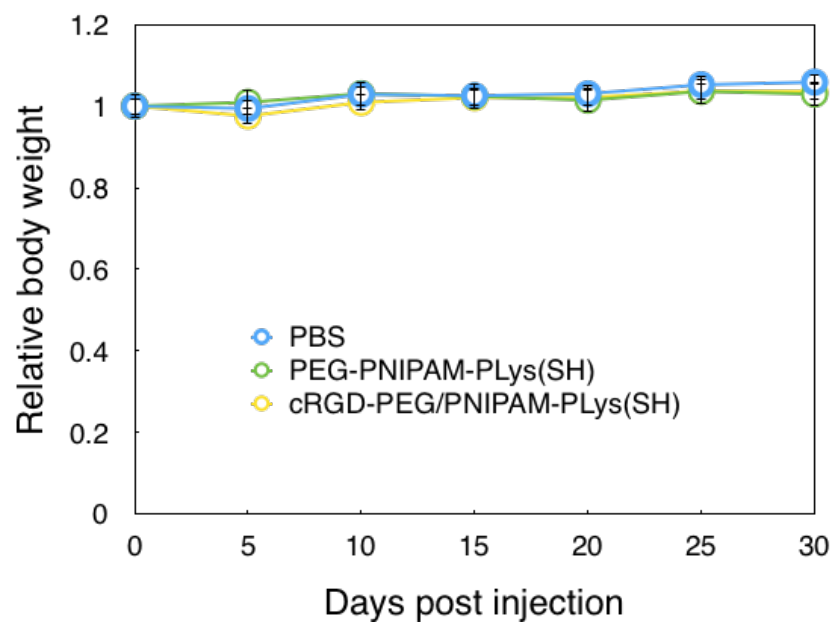

Figure S12 In vivo toxicity evaluation by monitoring body weight of Balb/c nude mice at three dosage of day 0,3 and 6 . 